\title{
Using emoji as a tool to support child wellbeing from a strengths-based approach
}

\author{
Jennifer Fane
}

Flinders University

jennifer.fane@flinders.edu.au

Keywords: emoji, children, child wellbeing, strength-based approach, child-centred research

\begin{abstract}
The assessment, measurement, and support of child wellbeing has garnered a substantive amount of research due to its widespread acceptance as the foundation of healthy development and future health and wellbeing. Despite this sustained interest, current understandings have derived almost exclusively from adult conceptualisations of wellbeing, contributing to the implicit and explicit exclusion of children's voices in child wellbeing research, policy, and practice. This has resulted in a fundamentally deficit view of children in relation to their health and wellbeing, where child health and wellbeing are benchmarked along developmental trajectories relating largely to skills and school readiness. Despite the pervasiveness of developmental perspectives of health and wellbeing in childhood, however, both national curricula, the Early Years Learning Framework (birth-to-five years of age) and the Australian Curriculum: Health and Physical Education learning area (AC:HPE) (foundation to year 10) (Australian Curriculum Assessment and Reporting Authority, 2013) highlight the need for children to be active and engaged participants in their own and others' wellbeing, and position children as beings who bring with them personal, relational, and community strengths and assets. This paper reports on a study that used emoji as a child-centred method for eliciting young children's $(n=78)$ perspectives of their own wellbeing. The findings of the study suggest that a range of young children are able to articulate their own understandings and experiences of wellbeing using emoji, and the value of this tool as a strengths-based approach for meeting curricular outcomes and supporting child wellbeing. This paper provides a rationale for the use of child-centred tools to re-position child wellbeing from a deficit to a strengths-based approach through the facilitation of children's exploration and communication of their own understandings and experiences of wellbeing.
\end{abstract}

\section{Introduction}

Increasingly, for young children, defined internationally generally as birth-to-eight (Copple \& Bredekamp, 2009), the concept of wellbeing has been operationalised to identify areas of need and risk in order to support the healthy development and wellbeing of young children (Fane, MacDougall, Redmond, Jovanovic, \& Ward, 2016). This construction of child wellbeing has led to the pervasive use of standardised assessments and large scale quantitative measures derived by adults, for young children, which have greatly informed knowledge, practice, and policy relating to child wellbeing. However, their almost exclusive use has implicitly and explicitly positioned and reinforced the idea of young children as having too limited "cognitive, language skills, and attention spans" (Hymel, LeMare, \& McKee, 2011, p. 270) to participate in the construction of knowledge surrounding child wellbeing. Yet, despite the continued exclusion of young children's 
voices and understandings of wellbeing within child research, there continues to be growing recognition of the need to reframe children's role within current conceptualisations of child wellbeing (Ballet, Biggeri, \& Comim, 2011; Biggeri \& Santi, 2012; Fattore, Mason, \& Watson, 2009; Fegter \& Richter 2014; Mashford-Scott, Church, \& Tayler, 2012).

The reframing of children's role within research and educational contexts requires recognising children as active citizens who, as enshrined in the United Nations Convention on the Rights of the Child (United Nations, 1989, p. 14) and stated in the guiding principles (United Nations International Children's Emergency Fund (UNICEF), 2014), "have the right to say what they think should happen and have their opinions taken into account...[and] seek, receive and impart information and ideas of all kinds...either orally, in writing, in print, in the form of art, or through any other media of the child's choice" (retrieved from: http://www.unicef.org/crc/ index_30177.html). However, if young children's views, understandings, and opinions are to be sought and listened to, tools and approaches which acknowledge and allow opportunities for the elicitation of children's understandings and experience are required. In this way strengthsbased approaches and tools that position children as knowledgeable and capable contributors to knowledge are essential in redressing their continued exclusion from our knowledge of children and childhood.

This paper reports on a research project which sought to investigate young children's understandings and experiences of wellbeing. The research project stems from the findings of a systematic review of young children's wellbeing during the transition to school (Fane et al., 2016), in which a key identified finding was that current conceptualisations of young children's wellbeing are almost exclusively derived from adult perspectives. To redress the exclusion of young children's voices in current constructions of child wellbeing, this study piloted the use of emoji as a strengths-based, child-centred research method to elicit young children's views and understandings of their own wellbeing. Emoji were determined to offer significant value to the growing suite of tools for constructing young children as co-researchers within childcentred and participatory research paradigms (Fane, MacDougall, Redmond, Jovanovic, \& Gibbs, 2016). This papers reports on the findings of the study in relation to the potential of emoji to support young children's engagement with both national curricula and to support their wellbeing within education and care contexts. The discussion centres on how emoji can be used within a strengths-based approach as a tool in research, classroom, and educational settings for supporting young children's current and future wellbeing, and to increase our knowledge of child wellbeing through the inclusion of children's perspectives.

\section{Literature review}

The use of visual research methods within child research may be seen to simply mimic activities children may do in the home or early childhood education and care settings (for example drawing, photography, using clay). However, there is a tradition of visual methods from the sub-discipline of visual sociology; the study of visible domains in social life, including the visual languages and sign systems through which we communicate (Emmison \& Smith, 2000). One of the core tenets of visual sociology asserts that the habitual activities of social life reveal what may be hidden or taken for granted in the inner mechanisms of ordinary life (Knowles \& Sweetman, 2004). As technology and media become an increasing part of young children's everyday experiences and environments, they offer a potentially fruitful avenue for examination of how methodology can react or respond to technological and social change.

Visual research has a strong link with technology and new technologies can contribute to and inform our knowledge about social worlds and actors (Cipriani \& Del Re, 2012). Emerging technologies have the potential to produce "new, innovative, reflexive, and theoretically 
informed" research (Pink, 2003, p.191), through its ability to accommodate different audiences and purposes. However, purposeful selection of visual materials requires careful attention to the visual material's likely impact on the intended audience (Jewitt \& Van Leeuwen, 2001). Exploration and engagement with technologies and digital literacies are becoming increasingly common-place in early education and care and school environments. These types of literacies, known as multiliteracies (Cope \& Kalantzis, 2009), offer fertile grounds for new visual methods for research with young children. The concept of multiliteracies extends traditional concepts of reading, writing, speaking, and listening to include symbols, icons, logos and multiple sign systems such as video clips (Department of Education and Children's Services, 2006). Contemporary sign symbols found in electronic and digital mediums may be relatively new, but their roles and use in conveying knowledge is indeed the oldest form of literacy (Chandler, 2007). The increased focus on multiliteracies and technology within curricula and designs for learning in early childhood education (Marsh, 2005) supports the use of emoji as a research method for engaging young children in how they understand and make meaning of their world. In this way, emoji offers both a practical and insightful approach to eliciting young children's voices in childhood research.

\section{Method}

\section{Participants}

Participants were 78 children (49 boys and 29 girls) aged 3-to- 5 years across eight early learning and long day care centres in metropolitan Adelaide, South Australia. The eight centres were chosen to represent a theoretical sample of the diversity of South Australian early childhood education and care services for preschool aged children in relation to socio-economic status (Australian Governement Commonwealth Grants Commission, 2012), and site type (standalone long day care centre or integrated long day care centre and primary school).

\section{Ethics}

Ethical research with young children is facilitated by a multi-step procedure for ensuring that both the research design and protocols are suitable, reasonable, and prioritise the safety and security of child participants. This four step process included ethics clearance from the researcher's university ethics committee, permission from centre directors, parental/guardian consent, and children's assent.

\section{Procedure}

The research design endeavoured to create sensitivity and proximity to build mutual trust and respect through repeated interactions with all child participants during multiple site visits. The final visit, and the focus of this paper, entailed the use of emoji as a visual research method in 13 focus groups across eight early learning and care services. All focus groups were audiorecorded and detailed field notes were recorded by the researcher at the end of each interview.

Emoji a type of graphic symbol, originating from Japan, which express concepts and ideas pervasively used in mobile communication and social media (Novak, Smailović, Sluban, \& Mozetič, 2015), were used as the sole data collection tool. Emoji are the descendent of the emoticon, a shorthand form of a facial expression created using a standard keyboard, for example :-) . Rather than keyboard shorthand, an emoji is an ideogram which can be used to represent a facial expression, but has been more widely co-opted to represent feelings, gestures, objects, animals, food and drink and activities (Novak et al., 2015). Emoji were 
modified for use with young children by enlarging them to $10 \mathrm{~cm}$ by $10 \mathrm{~cm}$, cutting them out individually, and laminating them so they could be manipulated by children. The researcher began by giving child participants five different emoji representing feelings through facial expressions (emoji 1-5 in Figure 1). Children were first asked to identify the feeling or emotion being portrayed by the five faces. Next, children were asked to pick one of the emoji, and tell a story about why someone might feel that way. After the participants had shared all the ideas they wanted with the researcher, the researcher gave each focus group 13 other emoji pictures, chosen to represent common objects, environments, activities, or iconography that young children would be familiar with (emoji 6-18 in Figure 2). Once the participants had the opportunity to explore the new emoji, they were asked to choose one and tell a story about it. The researcher engaged with every child's response throughout the focus group, asking clarifying questions if the response was not understood by the researcher, and repeating the child's idea or story back to ensure the researcher had correctly understood.

Figure 1. Emoji used in child focus groups.

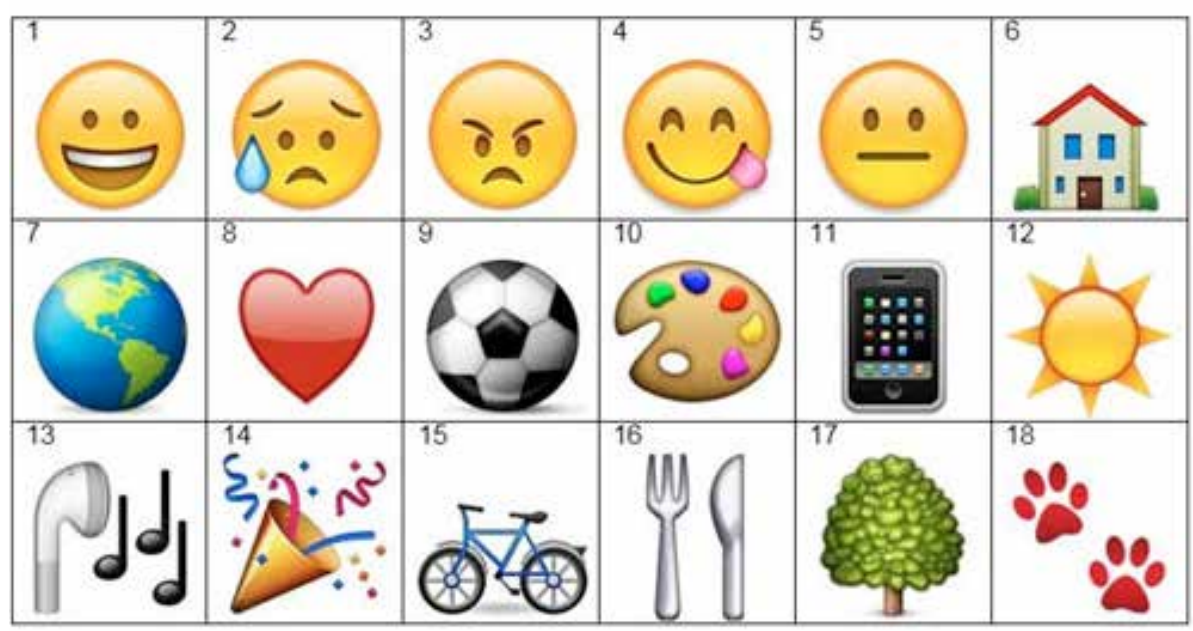

\section{Analysis}

A directed content analysis, an approach to qualitative content analysis deriving from relevant theory or research findings within the greater literature of the phenomena under study, was employed (Hsieh \& Shannon, 2005). During this initial coding phase, data that could not be coded using one of the predetermined codes were identified with a descriptive code to be analysed later, to determine if it represents a new category, or subcategory of an existing code (Hsieh \& Shannon, 2005). Data which did not fit within these existing six codes and identified with descriptive codes were then re-analysed and coded in a secondary round. This secondary round resulted in the further refinement of the descriptive codes into two additional categories.

The findings section reports on the ways in which the use of emoji in an educational context served as a strengths-based approach to supporting young children in exploring, sharing, and in some cases defending their own understandings of health and wellbeing. The discussion section will relate these findings to the two national curricula and why the use of innovative tools to engage student's in strengths-based approaches to child wellbeing are essential to the work of teachers and schools. 


\section{Results}

Eliciting children's voices and understandings

When given the five facial emoji (emoji 1-5 in Figure 1) and the verbal prompt "can you tell me what feelings you see?" at the beginning of the focus groups, the children generated twentyfour different feelings, emotions, and ideas (see Figure 2). Figure 2 illustrates the range of responses of what feelings were generated by the children in response to emoji 1 through 5 . Of particular interest was the volume and diversity of responses for the straight-mouthed emoji (i.e. emoji 5) that children shared. This emoji (i.e. emoji 5) also generated the most discussion between participants, and in four focus groups, generated disagreements and negotiations between children as to what feeling was being depicted. For example, the following excerpts from two separate focus groups highlights how children interpreted emoji differently and communicated their understandings to the researcher.

\section{Focus Group 2}

Researcher: [talking to Maisy ${ }^{1}$ who is holding the straight-mouth emoji] What is that feeling?

Maisy: Frustrated

Researcher: Oh frustrated, that's an interesting idea

Violet: No! That's bored!

Researcher: [speaking to the Violet] There are perhaps a lot of different emotions it could be, do you want to tell me a bored story in a minute? Right now I want to hear about Maisy's frustrated story. [turns to Maisy] When might you feel frustrated?

Maisy: When my friend got sick

Researcher: If your friend was sick. That would be frustrating. That's a really good idea, thank you. [turns to Violet] Violet did you want to tell me a story about feeling bored?

Violet: It's angry because, I changed my mind cause.... that boy pushed him, pushed him over

Researcher: Oh, somebody pushed someone, and that would make you feel angry?

Violet: Yes

\section{Focus Group 3}

Researcher: Does anyone have any ideas for what this feeling is? [holding up the straight-faced emoji]

Tom: Um straight

Researcher: The mouth is a straight mouth? Yes? [Tom nods], but how are they feeling?

David: Angry

Researcher: Maybe angry? That's a good idea.

Tom: No! Not angry! Because, because it hasn't got a sad face, look, upside down is a happy face [pointing to the emoji to indicate that the angry face has a downturned mouth and the happy face has an upturned mouth] 
In addition to generating the most discussion and disagreement, the straight-mouthed emoji (i.e. emoji 5) generated three to six times more feeling ideas than emoji 1 through 4 (see Figure 2). This suggests that while all the emoji allowed children opportunities to interpret the internal and external narratives of the symbols in a variety of ways with little adult/researcher input, the increased ambiguity of the symbol resulted in a greater amount of ideas, disagreement, and negotiations generated.

Figure 2. Ideas generated by three- to five-year-old child participants using emoji as a visual research method.

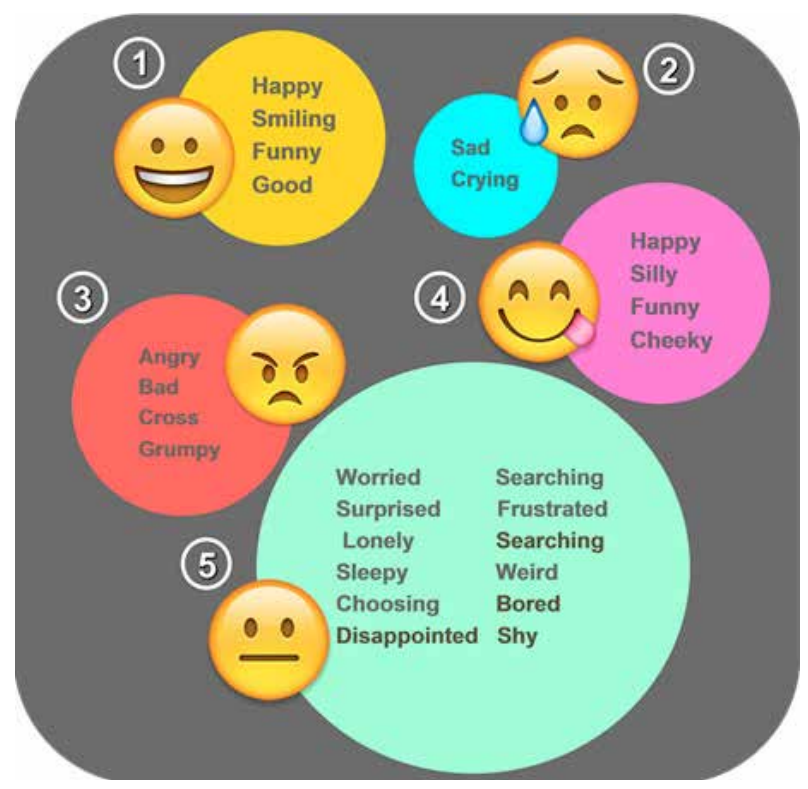

Supporting English as an additional language or dialect (EALD) speakers

All 78 children who participated in the focus groups were willing to pick up emoji of their choice at the researcher's request. The vast majority of children readily gave verbal responses to the researcher prompts or engaged in conversation and discussion with their peers about the emoji and the feelings and stories being shared. Instead of, or in addition to using verbal language, children used a variety of communication techniques including body language, noises/sounds, matching pictures together, and pairing pictures with their friends/peers. For children who were cautious about participating verbally, or had limited spoken English language abilities, the emoji offered a variety of ways for children to engage in the research process once they felt comfortable or had the language/vocabulary to express their ideas. The excerpt below is an example of how Ling, an EALD speaker, negotiated her participation in the research process using the emoji and a variety of non-verbal and verbal responses.

\section{Focus Group 6}

Researcher: Can everyone pick up an emoji? [all children in the focus group select an emoji] Ling, which one did you pick? Which feeling is that?

Emilio: Angry! Angry!

Ling: [no verbal response]

Researcher: That's an interesting idea Emilio. [speaking to Ling] Could this be an angry face? [Ling nods] 


\section{Multiple voices: Angry!}

Researcher: Ling do you have a story you'd like to share about why someone might feel angry?

Oscar: Cause someone called him silly

Researcher: Oh that's a good idea Oscar, but l'm wondering is Ling has an idea. Do you have a story you'd like to share? [Ling doesn't respond]. Should I come back and ask after? [Ling nods] Thanks Ling, l'll come back to you later to see if you want to share any ideas.

\section{[Later on in the focus group]}

Researcher: Who else would like to share an idea or story? Ling, would you like to tell me about the one you're holding?

Ling: Heart, that's heart [emoji 8]

Researcher: A heart. Thanks Ling. Would you like to tell me a story about the heart or how it might make someone feel?

Ling: [shakes head]

Researcher: Thanks Ling

Ling was eager to select an emoji and share her choice with her friends. She also readily responded to questions using non-verbal cues in the beginning of the focus group. The emoji offered a variety of ways for her to participate and share her ideas and feelings with her peers and the researcher without the need to communicate verbally in English. As EALD speakers commonly experience being excluded from the research process (Frayne, Burns, Hardt, Rosen, \& Moskowitz, 1996), children, who already as a group have been largely excluded from research, (Chaplin, 1994; Harrison, 2004; Klerfelt, 2007), who are EALD speakers are likely to be even further silenced. Later on in the focus group, however, after watching and listening to her peers respond, Ling did respond verbally to identify the emoji she had chosen. Ling was visibly proud of her verbal contribution to the group, and when another child chose the same emoji afterwards she indicated that they were the same while repeating "that's heart". The emoji were used in a variety of ways by Ling and other children to convey children's ideas and the images' importance to them, presenting opportunities for children to engage in the research process in the ways they wanted and/or were able to.

\section{Supporting children with special needs}

Several children seemed challenged by the concept of telling a story about a feeling, especially for the more ambiguous emoji, often waiting to let another child go first to tell a story about a particular emoji and use the previous example to build upon. Marcus, a child with special needs, actively participated from the beginning of the focus group, however, when prompted to tell a story, would instead re-identify the emoji he had chosen. While recent years have seen an increasing involvement of young children with special needs within childhood research, they have often been relegated to, or have occupied passive roles, with their participation being largely tokenistic (Gray \& Winter, 2011; Shier, 2001). Marcus' engagement with the emoji, however, was far from passive. Despite the initial challenges for Marcus in moving past description to storytelling, by the end of the focus group Marcus was able to communicate an example of how he might feel and offer a significant insight into how he conceptualises feeling well. 


\section{Focus Group 9}

Researcher: Great ideas, everyone. Marcus, can you tell me a story about this one? Why somebody might feel happy or silly?

Marcus: Silly

Researcher: Can you tell me a story about why someone might feel silly?

Marcus: There's a silly one and an angry

Researcher: Interesting ideas, they're showing different feelings. Thanks Marcus, I really appreciate your ideas.

Marcus: I want this one [referring to emoji Number 4]

Researcher: You'd like to hold that one?

Marcus: Yeah

Researcher: Ok, you hold onto that one, and l'll come back to you to see if you'd like to tell me a story about that feeling.

\section{[Later on in the focus group]}

Researcher: Reid, can you tell me a story about feeling sad?

Reid: This week

Researcher: Did you feel sad this week? Can you tell me what made you feel sad?

Marcus: I've been sad

Lee: A creature bite you

Researcher: Lots of interesting ideas...[interrupted by Marcus]

Marcus: I've been sad!

Researcher: I want to hear your ideas in a minute Marcus, but l'd like to let Reid finish his story? Reid when did you feel sad?

Reid: Someone hit me

Researcher: You would feel sad if someone hit you? That would make me feel sad too, thanks for sharing Reid. Marcus, did you want to tell me your story about when you felt sad?

Marcus: I missing my mum

Researcher: [didn't quite understand what Marcus said] When you were with your mum?

Marcus: I tell me mum

Researcher: You would tell your mum if you are feeling sad? That's an excellent idea. What would your mum do if you tell her you're feeling sad?

Marcus: And gives me medicine

Researcher: She gives you medicine? If you are sick?

Marcus: Yes 
During the focus group children were prompted on a number of occasions to pick an emoji, describe their choice and tell a story. The extract above shows how this supported Marcus to move from a simple description of the emoji to connecting his own experiences and feelings through storytelling. In this way, the repeated, yet open-ended nature of the emoji and the focus group procedure allowed opportunities for participation for children who were easily able to communicate their ideas and stories verbally, and children who required further support and modelling from peers.

\section{Discussion}

Through analysis of the data, it is clear that the use of emoji in educational contexts strongly supported young children in exploring and expressing their understandings of wellbeing. A key reason for this is due to the open ended nature of the use of emoji symbols, which allowed opportunities for young children to construct meaning and share their understandings with their peers, educators and researcher without concern for identifying the 'correct' answer, or sharing what they thought the researcher was asking of them. The use of open ended tools not only supported participant's engagement through the use of child led/initiated learning, a key tenant of early childhood education programs in Australian and internationally (Thomas, Warren, \& deVries, 2011; Wood, 2009), but also aligns with the aims and key strategies of both national curricula in regards to the use of strengths-based approaches which "affirm that all students and their communities have particular strengths and resources that can be nurtured" (Australian Curriculum Assessment and Reporting Authority, 2013, retreived from: http://www.australiancurriculum.edu.au/health-and-physical-education/key-ideas) and are highlighted as a key strategy for supporting child health and wellbeing.

The Early Years Learning Framework (Australian Government Department of Education, 2009) outlines the key practices which underpin good pedagogical practice in early childhood. One of these practices, entitled 'Responsiveness to children', requires educators to "value and build on children's strengths, skills, and knowledge...[including] children's expertise, cultural traditions, and ways of knowing" (Australian Government Department of Education, 2009, p. 14). Similar language is found in the AC:HPE (Australian Curriculum Assessment and Reporting Authority, 2013) where five interrelated propositions shape both the content and pedagogies underlying the curricular document.

The use of emoji as a tool to engage young children in developing their understanding and communication of key curricular concepts like safety, relationships, and feelings stem from a strengths-based approach because they offer children opportunities to communicate their understandings without having to start from adult conceptualisations of these concepts. This imbues children with affirmation of their understandings as distinct from that of adults and that these understandings are valued. As a shared goal of both curricular frameworks is the use of a strengths-based approach to support child health and wellbeing, emoji offer a tool that works across contexts for children of varying ages and would allow for continued engagement with key concepts, offering a flexible system for children to communicate feelings and needs to peers and teacher/educators. While this paper reports on the use of emoji within a research study, its applicability to early years learning contexts and schools is clear when mapped across both curricula. The continued focus on child led/ initiated learning provides a strong rationale for the use of emoji to move understandings of child wellbeing from a deficit to a strengths-based approach. 


\section{Conclusion}

Findings of this study highlight the potential of emoji for supporting children in engaging with both national curricula from a strengths-based approach, alongside supporting their overall wellbeing. As child wellbeing continues to be framed in largely deficit terms from adult perspectives, there is a significant need to redress young children's exclusion from present constructions to broaden current knowledge and understanding of child wellbeing. In addition, and of key importance, is also how using a strengths-based approach to child wellbeing can also support the work of teachers/educators and schools/early learning and care environments in creating learning environments supportive of child wellbeing that value children's knowledge and input. The open-ended nature of emoji not only supports a strengths-based approach, but also offers a high level of flexibility for its use across educational contexts, and ages and abilities of children. The use of child-centred visual materials, underpinned by a strengthsbased approach to defining, engaging with, and supporting child wellbeing, offers not only new and innovative approaches to meeting curricular outcomes, but also in re-defining current constructions of child wellbeing which impact significantly on the early childhood and education sectors and the work of teachers and educators. 


\section{References}

Australian Curriculum and Reporting Authority (ACARA). (2013) Australian Curriculum. Version 8.3. Retrieved from http://www.australiancurriculum.edu.au/

Australian Governement Commonwealth Grants Commission. (2012). Measuring socio-economic status: A discussion paper. (CGC 2012-03). Canberra.

Australian Government Department of Education, Employment and Workplace Relations. (2009). Belonging, Being \& Becoming: The Early Years Learning Framework for Australia. Canberra, ACT: Commonwealth of Australia,.

Ballet, J., Biggeri, M., \& Comim, F. (2011). Children's agency and the capability approach: A conceptual framework Children and the capability approach (pp. 22-45): Springer.

Biggeri, M, \& Santi, M. (2012). The missing dimensions of children's well-being and well-becoming in education systems: Capabilities and philosophy for children. Journal of Human Development and Capabilities: A Multi-Disciplinary Journal for People-Centred Development, 13(3), 373-395. doi: 10.1080/19452829.2012.694858

Chandler, D. (2007). Semiotics: the basics. London: Routledge.

Chaplin, E. (1994). Sociology and visual representation. London: Routledge.

Cipriani, R., \& Del Re, E. C. (2012). Imagination and society: the role of visual sociology. Cogn Process, 13 Supp/ 2, 455-463. doi: 10.1007/s10339-012-0433-4

Cope, B., \& Kalantzis, M. (2009). "Multiliteracies": New Literacies, New Learning. Pedagogies: An International Journal, 4(3), 164-195. doi: 10.1080/15544800903076044

Copple, C., \& Bredekamp, S. (2009). Developmentally appropriate practice in early childhood programs serving children from birth through age 8 (Vol. 22205-4101). Washington, DC.

Department of Education and Children's Services. (2006). Mapping multiliteracies: A professional learning resource. Hindmarsh, SA: DECS Publishing.

Emmison, M., \& Smith, P. (2000). Researching the visual: Images, objects, contexts and interactions in social and cultural enquiry. Emmison, P. Smith-London: Sage Publications.

Fane, J, MacDougall, C, Redmond, G, Jovanovic, J, \& Gibbs, L. (2016). Exploring the use of emoji as a visual research method for eliciting children's voices in childhood research. Early Child Development and Care. doi: http://dx.doi.org/10.1080/03004430.2016.1219730

Fane, J, MacDougall, C, Redmond, G, Jovanovic, J, \& Ward, P. (2016). Young children's health and wellbeing across the transition to school: A Critical Interpretive Synthesis. Children Australia, 41(2), 126-140. doi: 10.1017/cha.2016.4

Fattore, T., Mason, J., \& Watson, E. (2009). When children are asked about their well-being: Towards a framework for guiding policy. Child Indicators Research, 2(1), 57-77. doi: 10.1007/ s12187-008-9025-3

Fegter, S., \& Richter, M. (2014). Capability approach as a framework for research on children's wellbeing Handbook of Child Well-Being (pp. 739-758): Springer.

Frayne, S. M., Burns, R. B., Hardt, E. J., Rosen, A. K., \& Moskowitz, M. A. (1996). The exclusion of nonEnglish-speaking persons from research. Journal of General Internal Medicine, 11(1), 39-43.

Gray, C., \& Winter, E. (2011). Hearing voices: participatory research with preschool children with and without disabilities. European Early Childhood Education Research Journal, 19(3), 309-320. doi: 10.1080/1350293x.2011.597963 
Harrison, B. (2004). Photographic visions and narrative inquiry. In M. Bamberg \& M. Andrews (Eds.), Considering counter - narratives: Narrating, resisting, making sense. Amsterdam: John Benjamins Publishing Company.

Hsieh, H., \& Shannon, S. E. (2005). Three approaches to qualitative content analysis. Qualitative Health Research, 15(9), 1277-1288.

Hymel, S., LeMare, L., \& McKee, W. (2011). The early development instrument: An examination of convergent and discriminant validity. Social Indicators Research, 103, 267-282. doi: 10.1007/ s11205-011-9845-2

Jewitt, C., \& Van Leeuwen, T. (2001). Handbook of visual analysis. Cape Town: Sage Publications.

Klerfelt, A. (2007). Gestures in conversation - the significance of gestures and utterances when children and preschool teachers create stories using the computer. Computers \& Education, 48(3), 335361. doi:10.1016/j.compedu.2005.02.001

Knowles, C., \& Sweetman, P. (2004). Picturing the social landscape: Visual methods and the sociological imagination. London: Routledge.

Marsh, J. (Ed.). (2005). Popular culture, new media and digital literacy in early childhood. London: RoutledgeFalmer.

Mashford-Scott, A., Church, A., \& Tayler, C. (2012). Seeking Children's Perspectives on their Wellbeing in Early Childhood Settings. International Journal of Early Childhood, 44(3), 231-247. doi: 10.1007/ s13158-012-0069-7

Novak, P. K., Smailović, J., Sluban, B., \& Mozetič, I. (2015). Sentiment of emojis. PLoS ONE, 10(12). doi: 10.1371/journal.pone.0144296

Pink, S. (2003). Interdisciplinary agendas in visual research: re-situating visual anthropology. Visual Studies, 18(2), 179-192. doi: 10.1080/14725860310001632029

Shier, H. (2001). Pathways to participation: Openings, opportunities and obligations. Children \& society, 15(2), 107-117.

Thomas, L., Warren, E., \& deVries, E. (2011). Play-based learning and intentional teaching in early childhood contexts. Australasian Journal of Early Childhood, 36(4), 69.

UNICEF. (2014, August 7th 2014). Rights under the Convention on the Rights of the Child: Guiding Principles. from http://www.unicef.org/crc/index_30177.html

United Nations. (1989). United Nations Convention on the Rights of the Child (UNCRC). Retrieved from: www.ohchr.org/en/professionalinterest/pages/crc.aspx.

Wood, E. (2009). Conceptualizing a pedagogy of play: International perspectives from theory, policy and practice. From children to Red Hatters: Diverse images and issues of play, 8, 166-189. 